RESEARCH-IN-MOTION

\title{
The Role of Sport-Life Balance and Well-Being on Athletic Performance
}

\author{
Katrina Monton \& Anna-Maria Broomes \\ Desautels Faculty of Management, McGill University \\ Sophie Brassard \\ Canadian Olympic Committee, Game Plan Program \\ Patricia Hewlin, Ph.D \\ Desautels Faculty of Management, McGill University
}

\begin{abstract}
The present study explores the role of sport-life balance and well-being on athletic performance. Canadian athletes who competed at the 2019 Pan American and Para Pan American Games in Lima, Peru were invited to participate in the survey via email. A mixed-methods design was utilized, consisting of an online survey and semi-structured, follow-up interviews. The sample consisted of 72 athletes, spanning eighteen different sports. Our findings demonstrate that while many Olympic and Paralympic athletes are successful in maintaining a strong support network, significant concerns arose regarding meagre finances, a lack of free time, and minimal support both within and outside of sport. Perspectives on the benefits of sport-life balance on performance were mixed, with the majority of athletes revealing that they were unsure of the benefits, did not experience benefits, or experienced negative effects. Feelings of dissatisfaction with performance, experiences of being overwhelmed in managing an athletic career, and tensions in developing a self outside of sport
\end{abstract}

were prevalent among the athletes.

Keywords: Sport, well-being, athletic transitions, career transition, sport-life balance, support, performance

High level athletes can devote decades of their lives to sport, but no matter how much time they have invested, retirement from one's athletic career is inevitable. For many athletes, the rigorous travel and training schedule prevents them from pursuing other interests while training and competing. This demanding regimen can often lead athletes to experience a lack of balance and limited opportunities to develop an identity outside sport, which inevitably makes the transition from sport more challenging. In recent years, there has been a heightened awareness of the struggles athletes face, during and upon retirement from sport due to an increase in media coverage of athlete stories regarding mental health, well-being and career transitions. Naomi Osaka is an American tennis all-star and one of the world's highest paid female athletes (Kelly, 2021). Recently, she garnered worldwide attention when she opted out of major world tennis competitions (Kelly, 2021). Osaka has since shared that she felt it necessary to re-establish balance and prioritize her mental and physical health. Canadian athletes like Tom Hall, Krista Guloien and Alexandre Bilodeau, Olympic medalists in canoe-kayak, rowing and alpine skiing, have spoken out and shared their difficulties in finding their identity beyond sport. Hall describes coping with the lack of purpose post sport; "the sense of purposelessness gnawed deeper. I hated what I had become. I had gone from an Olympianconfident, gifted, and fit — to an overweight insomniac with no direction." (Hall, 2019). These experiences are shared by many athletes worldwide. The study of how sport-life balance or lack thereof thus has important implications for athletes' emotional wellbeing both during and after sport.

\section{Literature Review}

Research in sports-life balance for athletes has been steadily increasing over the past three decades (Park et al., 2013). In recent years there has been a push to consider a more holistic 


\section{The Role of Sport-Life Balance and Well Being 102}

perspective of athletes as human beings, extending beyond their athletic identities and performance ability (Friesen \& Orlick, 2010; Park et al., 2013). Current literature suggests having sport-life balance facilitates athlete well-being and improves sport performance (Friesen \& Orlick, 2010; Pink et al., 2015). Knapp (2012) echoes this, and states that student-athletes participating at the Olympic Games are more likely than their non-student counterparts to win medals. Student-athletes believe that balancing sport and academics not only benefits performance in both areas but promotes future career success as well (Aquilina, 2013). Contrarily, athletes who lack balance are more susceptible to increased levels of fatigue, stress and burnout, ultimately impacting performance (Vallerand \& Verner-Fillion, 2020).

Transitioning out of elite sport forces an individual to adjust to a new way of life and can often be accompanied by negative effects, impacting mental health (Knights et al., 2016; Ohashi, 2018). However, retiring from sport and pursuing other experiences are critical and necessary life events that can positively impact the individual and lead to personal growth, development and fulfillment (Ohashi, 2018). Athletes who have opportunities to explore their interests and identity beyond sport, developing both vocational and life skills, report more ease with athletic career transition, adapting more easily to a new routine and way of life (Gordon \& Lavallee, 2012; Hansen, et al., 2018;
Knights et al., 2016; Park et al., 2013; Pink et al., 2015). Athletes who lack balance and non-sporting experiences, report experiencing delayed identity shifts, increased stress and ultimately find it more difficult to adjust to life after sport (Park et al., 2013). Planning for life after sport and the use of career counselling and psycho-educational programs, have been shown to have a positive impact on sport performance, as well as increased life and career satisfaction, post-sport (Aquilina, 2013; Knights et al., 2016; McArdle et al., 2014; Ohashi, 2018; Park et al., 2013). Additionally, Park et al. (2013) report that psychosocial support from those close to athletes, including family, friends, coaches, trainers and teammates, has been shown to positively impact athlete career transition by easing emotional distress and increasing athletes' self-esteem and sense of belonging through social networks.

\section{Purpose}

The purpose of this study is to explore the role of sport-life balance and well-being on athletes performance at the 2019 Pan American and Para Pan American Games. It is the first of a series of post-game debrief studies for Pan American and Para Pan American Games. These post-Pan/Para Pan American debrief studies will seek to further our understanding about the role of athlete well-being, sport-life balance and performance at major games through the collection and comparison of longitudi- nal data. These debrief surveys are conducted in collaboration with the Canadian Olympic Committee's Game Plan Program, which strives to support current and retired national team athletes to lead more balanced lifestyles, with a focus on health, education, and career opportunities for athletes' high-performance careers and beyond. This project is an important contribution for Canadian athletes, as it will not only expand our understanding of these phenomena within the current landscape, but help to inform the Game Plan Program on how they may better meet the needs of transitioning athletes and promote overall athlete well-being.

\section{Methods}

This study employed a mixed-methods research design consisting of an online survey, and a series of semi-structured, follow-up interviews. The survey was designed to investigate how Canadian athletes who had competed at the 2019 Pan American and Para Pan American Games, in Lima, Peru, felt about how prepared they were for life leading up to, and after, the Games. Game Plan administrators sent the survey via email to all eligible national team athletes who competed at the 2019 Pan American and Para Pan American Games. At the end of the survey, there was the option for athletes to volunteer to participate in the follow-up interviews. Interviews were semi-structured and lasted approximately 30 minutes. 


\section{Participants}

Canadian athletes who had competed at the 2019 Pan American and Para Pan American Games in Lima, Peru were invited to participate in the study. The population from which the participants were sampled consisted of 475 athletes. A sample of 72 athletes (15\% response rate) participated in the quantitative survey, spanning eighteen different sports. Among them were 47 Olympic athletes, 14 Paralympic and 11 who did not identify the games in which they participated. The final sample consisted of 22 male athletes, 40 female athletes and 10 athletes who did not specify. A sample of 6 athletes (3 Olympic and 3 Paralympic) participated in the follow-up qualitative interviews.

\section{Sport Affiliation}

The following sports were represented: athletics, basketball, boxing, canoe/kayak, cycling, equestrian, field hockey, gymnastics, handball, para-cycling, para-swimming, racquetball, shooting, softball, surfing, taekwondo, volleyball and wheelchair rugby.

\section{Education}

At the time of data collection, 25 of the athletes surveyed were currently enrolled in school, while 36 were not. Athletes' highest level of educational attainment varied (i.e., 10 high school, 7 college, 3 professional designation, 37 university, 4 post graduate and 11 unidentified).

\section{Analysis}

All quantitative analyses were performed using RStudio Version 1.2.5033 software. We conducted descriptive analysis, focusing on frequency distributions, to summarize the sample data and detect sample characteristics that may help influence future data collection and analysis. We reviewed the interview data to identify key athletic concerns and provide a richer contextualization of the survey findings.

\section{Results}

\section{Survey Results}

\section{Goal Achievement and Games Satisfaction}

Respondents were asked if they achieved their personal performance goal(s) for the Lima 2019 Pan American or Para Pan American Games and how satisfied they were with their overall experience at the Games (Figure 1. $62 / 72$ athletes responded $(86.1 \%)$ to the questions. Most respondents at least partially achieved their goals, with $29 \%$ of athletes responding "Yes", and $38.7 \%$ of athletes responding "Somewhat". Nearly a quarter of athletes did not achieve their personal performance goals. Most of the athletes were at least somewhat satisfied with their performance at the games with only two responding that they were Extremely dissatisfied or Dissatisfied. Over two-thirds of the athletes responded that they were Extremely satisfied (16) or
Satisfied (28) with their overall experience at the 2019 Pan American and Para Pan American Games. Eleven athletes were Somewhat satisfied and three were Satisfied, while two were Neither satisfied or dissatisfied.

\section{Sport-Life Balance}

Athletes were asked to rate their ability to effectively manage their sporting commitment with other areas of their life, such as academics, work, volunteering, social life, and personal/professional development. Results show that during a normal season, approximately three quarters of athletes $(75.8 \%)$ feel at least somewhat balanced. Several athletes responded that during a normal season they have difficulty managing sporting and non-sporting commitments, their sport-life balance is unbalanced $(6.9 \%)$ or somewhat unbalanced (8.6\%). However, no athletes responded that their sportlife balance was extremely unbalanced.

Prior to the games, the majority of athletes (58.6\%) also responded that their sports-life balance was at least somewhat balanced (Figure 2). However, twenty athletes $(34.4 \%)$ responded that they were somewhat unbalanced, unbalanced or extremely unbalanced.

In rating their sport-life balance currently, after the 2019 Pan American and Para Pan American Games, over seventy percent of athletes responded having at least somewhat balanced sportlife balance. Five of those ath- 


\section{Figure 1}

\section{Games satisfaction}

How satisfied are you with your overall experience at the Games?

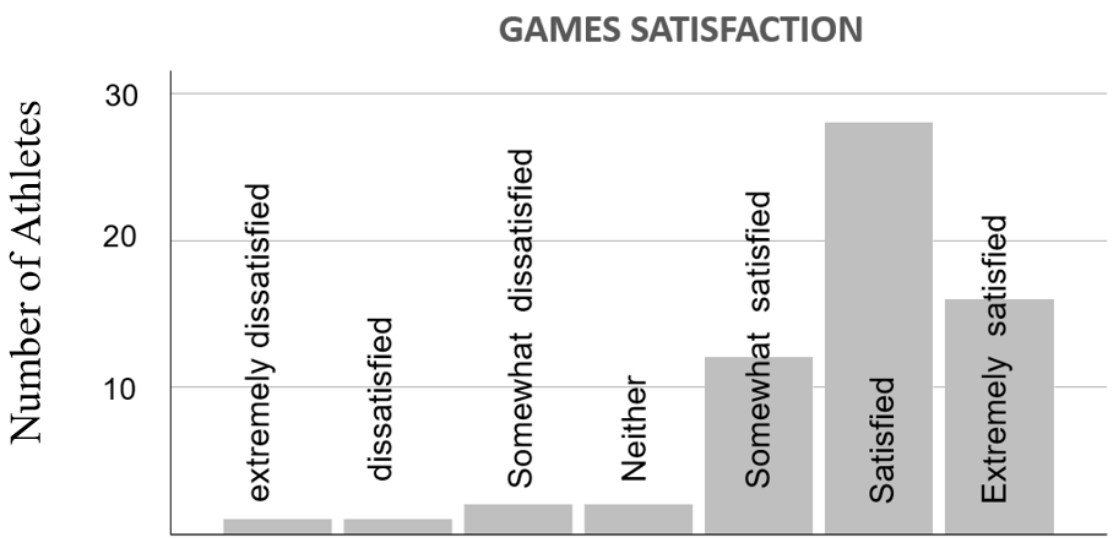

Figure 2

Current sport-life balance after the games and sport-life balance prior to the games

Rate your sport-life balance

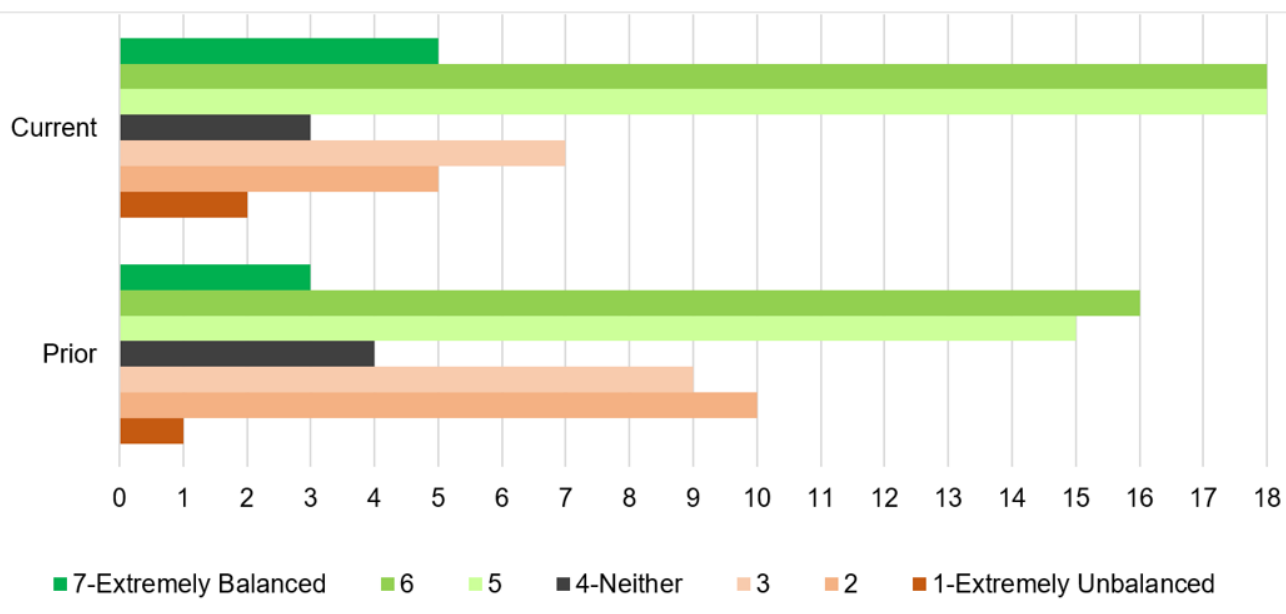

Number of Athletes

letes $(8.6 \%)$ responded that their sport-life balance was extremely balanced. Nearly a quarter of athletes $(24.1 \%)$ responded that their sport-life balance was somewhat unbalanced or worse.

\section{Sport-Life Balance and Performance}

After rating their sportslife balance, respondents were asked about the effect of this sportlife balance on their performance at the 2019 Pan American and Para Pan American Games. Elev- en athletes responded don't know/ unsure (19.0\%) and twelve athletes responded no effect (20.7\%), which suggests the opportunity to educate athletes about balance-performance links. Twelve athletes responded that sport-life balance had a negative effect on their performance; fifty percent of whom responded somewhat unbalanced to their sports-life balance before the Games. Of the seventeen athletes who responded that sportslife balance had a positive effect on their performance at the games, five athletes $(29.4 \%)$ were somewhat balanced before the games, seven athletes were balanced before the games $(41.2 \%)$ and two athletes (11.6\%) were extremely balanced.

\section{Support for Sport-Life Balance}

Support of sport/ life balance was assessed by several questions in the Debrief Survey. In answering who (other than potentially their advisor) has helped them work on their sport/life balance, most athletes responded Family (42 athletes) and Friends (33 athletes). Professional allies in sport, including Coach[es] (25 athletes), Teammate [s] (25 athletes) and Sport Psychologists[s]/ Mental Performance Consultant [s] (24 athletes) and Mentor [s] (13 athletes) were popular support networks for athletes. Advisor [s] (9 athletes), Agent [s] (2 athletes), Counsellor [s] (3 athletes), and National Sport Organization Staff 
Figure 3

Support of coaching staff of non-sport pursuits prior to the games and in general

Support of Coaching Staff of Non-Sport Pursuits

\section{HOW SUPPORTIVE WAS YOUR COACHING STAFF OF YOUR NON-SPORT PURSUITS}

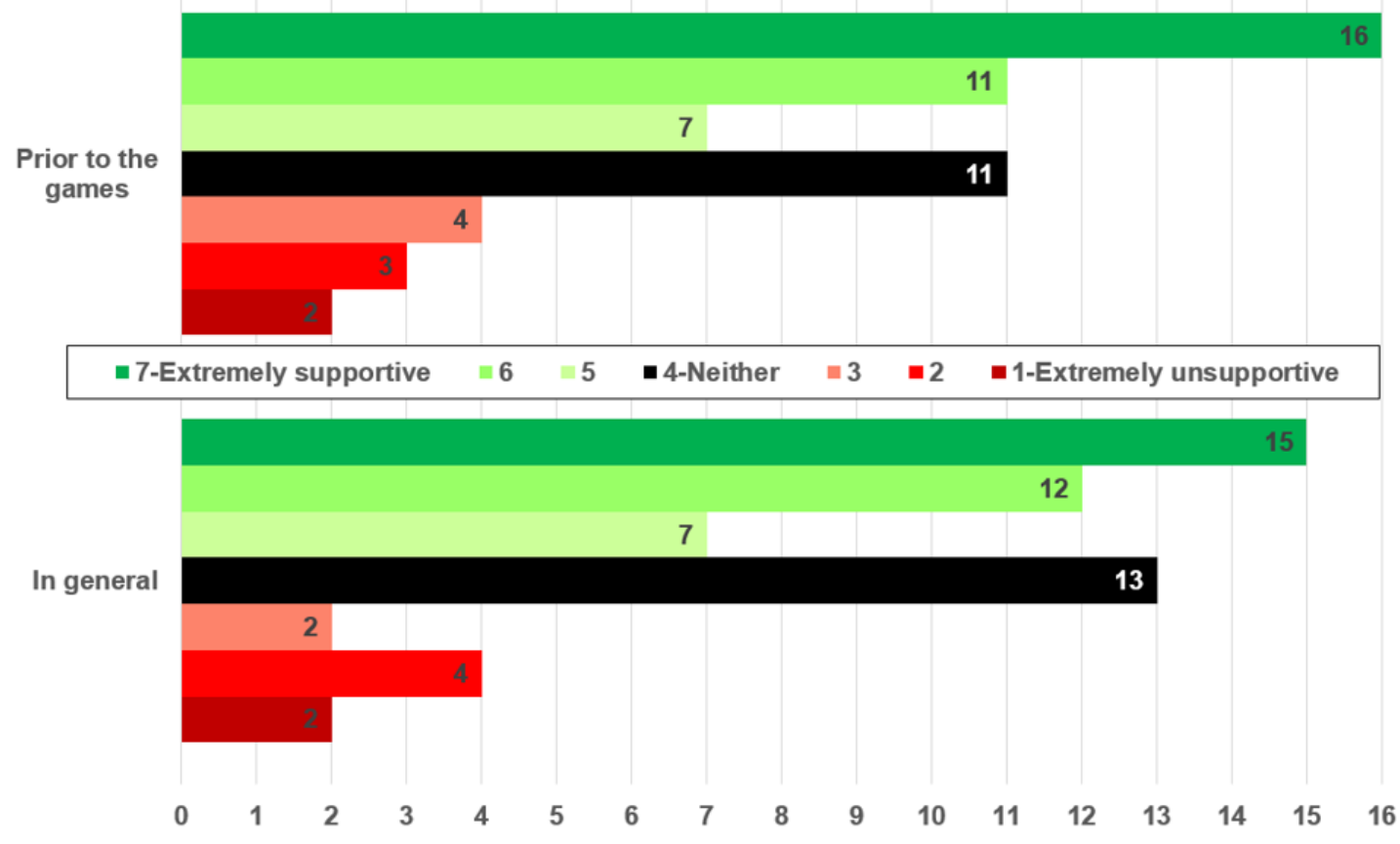

somewhat supportive (13.0\%), supportive (20.4\%) or extremely supportive $(29.6 \%)$. Nine athletes (16.7\%) responded that their coach was less than supportive of their non-sport pursuits and eleven $(20.4 \%)$ responded that their coach was neither supportive or unsupportive. Notably, out of the twenty athletes who did not respond that their coach was supportive in the 12 months leading up to the games, only 3 $(20 \%)$ responded that they achieved their goals at the 2019 Pan American and Para Pan American Games.

\section{Qualitative Insights}

Through an exploratory cent of athletes $(14.5 \%)$ responded that their coach was somewhat unsupportive (3.6\%), unsupportive (7.3\%), or extremely unsupportive $(3.6 \%)$

In the 12 months leading up to the Games, the distribution of responses is similar to coaching support of non-sport pursuits in general. A total of thirty-four out of the fifty-four respondents $(63.0 \%)$ stated that their coach was

\section{review of the interview data, we} identified key concerns pertaining to athletes' sport-life balance, education and support systems.

\section{Sport-Life Balance}

Athletes shared they found it challenging at times to balance sport and life responsibilities simultaneously. One athlete 


\section{The Role of Sport-Life Balance and Well Being 106}

shared, "The balancing act with full time classes and training is always tough. I find myself often thinking about school stuff while at training and I want to be just focusing on my sport". Furthermore, two athletes shared that having accommodations and/or flexibility at school/work, was helpful in attaining some degree of sport-life balance. Despite the challenges associated with finding balance, five of the six athletes expressed they had better mental health when they had some degree of balance: "For me having a focus, even if it wasn't work, even if it was just like something to do after so there isn't just open space and time is good".

\section{Education}

Athletes expressed the importance of pursuing education. One athlete shared, "I feel pretty lucky that I have, that I took the time and foresaw that having an education, even though it was hard while I was training full time, that it would pay off". However, two athletes shared that although they were pursuing their education, they lacked non-sport experiences, and had some level of uncertainty regarding life after sport.

\section{Support}

Unanimously, athletes shared they received a lot of highly valued support from family. Athletes had mixed responses when asked about support from coaches and sport organizations, related to sport-life balance and non-sport pursuits. Some athletes expressed they felt supported, while others expressed that coaches and sports organizations deterred the athletes from non-sport pursuits. One athlete described this; "In my experience they [national sport organization/coaches] are definitely not supportive of athletes that want to take full time classes at the same time that they are training".

\section{Discussion}

\section{Athlete Balance}

The majority of athletes reported being able to maintain some level of sport/life balance leading up to and during the Games. There was a slight increase in lack of balance during the Games, which is understandable as many athletes reported that they prefer to focus solely on sport during competition. Interestingly, athletes reported a significant increase in difficulty finding balance post-Games. This is consistent with existing research that suggests athletes who participate in major games can experience a post-game let down, which is often referred to as "post-games blues" (Henriksen et al., 2020). Post-games can be a time of increased vulnerability for athletes as they are often mentally and physically exhausted, have been disconnected from family and friends, and experience a less regimented schedule, all of which contribute to difficulty finding of balance (Henrikson et al., 2020; Dehghansai et al., 2021).

When athletes were asked about the effects that their sport/ life balance had on their performance at the 2019 Pan American and Para Pan American Games, nearly half reported they were either unsure or believed there was no connection between the two. This suggests that a large portion of athletes are unaware of the positive impact that sport-life balance can have on their performance at major Games. Interestingly, a smaller subset of athletes responded that sport-life balance hurt their performance, which may be due to the perception that non-sport pursuits act as a distraction. Half of those athletes had also reported feeling somewhat unbalanced leading up to the Games. These results suggest there may be an opportunity for more athlete education and outreach, specifically related to the link between sport/ life balance and overall performance.

\section{Support}

Overwhelmingly, athletes felt they received the most support from family and friends. These results exemplify the importance of athletes' external support systems. Game Plan might consider the integration of family and friends within the services provided to athletes. For example, Game Plan may consider developing programs such as Webinars for Loved Ones to help foster and facilitate communication among athletes and their external support about sport and non-sport interests alike. This may also help athletes prioritize their lives outside of sport.

In addition to family and 
friends, athletes reported they felt supported by coaches, teammates and sports psychologists. Leading up to the games, most athletes reported they felt their coach was supportive. Interestingly, of the athletes who felt their coach was extremely supportive, $80 \%$ were satisfied or extremely satisfied with their overall performance at the games. These results demonstrate the importance of the relationship between coach and athlete.

Nearly a quarter of athletes reported that their coach was neither supportive nor unsupportive of non-sport pursuits, while a quarter reported their coach was unsupportive to some degree. Additionally, of the athletes who reported this lack of coach support, only three athletes reported achieving their goals at the 2019 Pan American and Para Pan American Games. These results suggest that it would be valuable for coaches to receive education regarding the importance of sport/ life balance. Promotion of sport/ life balance among coaches might contribute to an increased understanding and support for athlete development and pursuits outside of sport.

\section{Limitations and Implications for Future Research}

The current study had a response rate of $15 \%$, only 72 of 475 athletes. Therefore, the results might not be representative of the athlete population. The low response rate may be due to a lack of monetary incentive for the survey completion and no follow-ups with targeted respondents. These issues will be addressed in future debrief studies. Additionally, post-games can often be a difficult time for athletes, it is possible this may have impacted the response rate.

This study is the first in a series of post Pan/Para Pan American Games debrief surveys, exploring similar themes. Future debrief studies will use similar validated scales and items, to collect longitudinal data regarding the role of sport-life balance and well-being on athletic performance. Although there is a growing body of related research, it would be beneficial to explore these phenomena further within the Canadian landscape of sport to tailor support programs to the unique needs of Canadian athletes. Future research in this area might lead to increased buy-in Game Plan's total athlete wellness philosophy from all stakeholders, including national sport organizations and coaches.

Evidenced by the survey results, coaches play a critical role in an athlete's sport/life balance and ultimately on their performance. As such it would be beneficial to consider a survey targeting coaches' perceptions about athlete balance and its impact on performance outcomes. Capturing coaches' perspectives about athlete non-sport pursuits would allow for more targeted and multipronged interventions as well as provide context to athlete's concerns and perspectives.

\section{References}

Aquilina, D. (2013): A Study of the Relationship Between Elite Athletes' Educational Development and Sporting Performance, The International Journal of the History of Sport, 30(4), 374-392

Dehghansai, N., Pinder, R. A., Baker, J., \& Renshaw, I. (2021). Challenges and stresses experienced by athletes and coaches leading up to the Paralympic Games. Plos one, 16(5), e0251171.

Friesen, A., \& Orlick, T. (2010). A qualitative analysis of holistic sport psychology consultants' professional philosophies. Sport Psychologist, 24(2), 227-244. Retrieved from http://journals.humankinetics. com/tsp

Game Plan. (2018). Retrieved March 22, 2019, from https:// www.mygameplan.ca/

Gordon, S., \& Lavallee, D. (2012). Career transitions. In T. Morris \& P. Terry (Eds.), The new sport and exercise psychology companion (pp. 567-582). Morgantown, WV: Fitness Information Technology.

Hall, T. (2019, November 18). When the Games Are Over. Retrieved August 19, 2020, from https://thewalrus.ca/ when-the-games-are-over/ Hansen, A., Perry, J., Ross, M., \& Montgomery, T. (2018). Facilitating a successful transition out of sport: Introduction of a collegiate student-athlete workshop. Journal of Sport 
Psychology in Action, 10(1), 1-9.

Henriksen, K., Schinke, R., McCann, S., Durand-Bush, N., Moesch, K., Parham, W. D., Larsen, C., Cogan, K., Donaldson, A., Poczwardowski, A., Noce, F., \& Hunziker, J. (2020). Athlete mental health in the Olympic/Paralympic quadrennium: a multi-societal consensus statement. International Journal of Sport and Exercise Psychology, 18(3), 391-408.

Kelly, J. (2021). Tennis Star Naomi Osaka Stood Up For Herself, Bravely Shared Her Mental Health Issues And Walked Away From The French Open. Forbes. Retrieved from https://www.forbes.com/ sites/jackkelly/2021/06/01/ tennis-star-naomi-osakastood-up-for-herself-bravely--shared-her-mentalhealth-issues-and-walkedaway-from-the-frenchopen/?sh=30a552f21e37.

Knapp, D. (2012). Performance of student-athletes at Olympic Games: The performance impact of university student-athletes at the 2004, 2008, and 2012 Olympic Games. Adcell Group, 1-36. Retrieved from http://adcellgroup.com.au/ development/uniroos/images/ Performance of student-athletes_at_Olympic_Games.pdf

Knights, S., Sherry, E., \& Ruddock-Hudson, M. (2016). Investigating elite end-of-athletic-career transition: A systematic review. Journal of Applied Sport Psychology,
28(3), 291-308.

McArdle, S., Moore, P., \& Lyons, D. (2014). Olympic athletes' experiences of a post games career transition program. The Sport Psychologist, 28(3), 269-278.

Miles, F. (2020, August 06). Michael Phelps, other athletes, open up about suicide and depression in new documentary. Retrieved August 17, 2020, from https://www. foxnews.com/sports/michael-phelps-suicide-depression-athletes-documentary Ohashi, Alison, "Transitioning Out of Sport: Perspectives of Student-Athlete Support or Development Services" (2018). Boise State University Theses and Dissertations. 1406. https://scholarworks. boisestate.edu/td/1406/

Park, S., Lavallee, D., \& Tod, D. (2013). Athletes' career transition out of sport: A systematic review. International review of sport and exercise psychology, 6(1), 22-53.

Pink, M., Saunders, J., \& Stynes, J. (2015). Reconciling the maintenance of on-field success with off-field player development: A case study of club culture within the Australian Football League. Psychology of Sport and Exercise, 21(1), 98-108.

Vallerand, R. J., \& Verner-Filion, J. (2020). Theory and research in passion for sport and exercise. Handbook of sport psychology, 206-229.

Wylleman, P., \& Lavallee, D. (2004). A developmental per- spective on transitions faced by athletes. In M. Weiss (Ed.), Developmental sport and exercise psychology: A lifespan perspective (pp. 507-527). Morgantown, WV: Fitness Information Technology. 